\title{
CHROMOSOMAL AND BIOCHEMICAL SCREENING ON MENTALLY RETARDED SCHOOL CHILDREN IN TAIWAN
}

\author{
Kuang-Dong WuU, ${ }^{1}$ Pao-Chin CHIU, ${ }^{2}$ Shuan-Yow LI, ${ }^{3}$ \\ Jia-Yuh Chen, ${ }^{4}$ Mei-Chyn CHao, ${ }^{5}$ Fang-Jong Ko, ${ }^{5}$ \\ Tso-Ren WANG, ${ }^{6}$ and Kwang-Jen $\mathrm{HsIAO}^{1}$
}

${ }^{1}$ Institute of Genetics, National Yang Ming Medical College, Taipei, Taiwan 'Department of Pediatrics, Veterans General Hospital at Kaohsiung, Kaohsiung, Taiwan

${ }^{3}$ Institute of Medicine, Chung Shan Medical and Dental College, Taichung, Taiwan

${ }^{4}$ Department of Pediatrics, Chung Shan Medical and Dental College Hospital, Taichung, Taiwan

${ }^{5}$ Department of Pediatrics, Kaohsiung Medical College Hospital, Kaohsiung, Taiwan

${ }^{6}$ Department of Pediatrics, National Taiwan University Hospital, Taipei, Taiwan

Summary Governmental officials as well as medical scientists in Taiwan have worked hard in recent years to develop and to implement various measures, such as prenatal diagnosis and neonatal screening, to lower the incidence of hereditary diseases and mental retardation in the population. An inquiry into the possibility of devising a chromosomal and biochemical screening program and to apply it routinely to all the mentally retarded school children island-wide was the major aim of the present study. A collection of 1,614 blood samples was screened for phenylketonuria (PKU), galactosemia, homocystinuria, biotinidase deficiency, and congenital hypothyroidism. The IQ of these children ranged from 50-75 (1,397 children, moderate group) to less than 50 (217 children, severe group). Six cases of PKU (one tetrahydrobiopterin deficient and five classical) and three cases of thyroid dysfunction were found. The overall incidence of these two diseases was $0.56 \%$. Of the 1,614 blood samples, 1,323 were cultured and karyotyped successfully. One hundred and twenty-five of them had chromosome abnormalities. The majority (64 out of 125) were trisomy 21 . A remarkable difference in the percentage of mentally retarded children with chromosome abnormalities was observed between the moderate $(7.87 \%)$ and severe $(17.51 \%)$ retardates. Key Words mental retardation, biochemical screening, chromosomal screening, phenylketonuria, galactosemia, homocystinuria, biotinase deficiency, congenital hypothyroidism

Received June 27, 1991; revised version received August 26, 1991, Accepted September 9, 1991 


\section{INTRODUCTION}

The etiology of mental retardation is often difficult to determine. It has been estimated that about $5 \%$ of the severely retarded cases, not including Down's syndrome, involve a hereditary component (Milunsky, 1975). Various surveys have been carried out in the past two decades in different parts of the world to karyotype patients with mental retardation (Sutherland and Wiener, 1971; Cassiman et al., 1975; Coco and Penchaszadeh, 1976; Speed et al., 1976; Sutherland et al., 1976; Jacobs et al., 1978; Moghe et al., 1981; Wuu et al., 1984). Some researchers have examined the chromosomes of all mental retardates in an institution (Jacobs et $a l ., 1978$ ) or in a regional population (Speed et al., 1976), while others have selected the patients before karyotyping (Coco and Penchaszadeh, 1976; Moghe et al., 1981). These studies unequivocally demonstrate that mentally retarded patients with associated congenital abnormalities have a higher frequency of chromosomal abnormalities than those without.

The incidence of biochemical disorders in mental retardates varies considerably in different surveys. Drillien et al. (1966) examined 391 children aged 7-14 years with mental handicaps in Edinburgh, and only five of them $(1.28 \%)$ were metabolically abnormal. Kelly and Swift (1967) screened 967 mentally retarded residents of the Rome (New York) State School for amino acid abnormalities, 11 phenylketonurics (1.14\%) were diagnosed. Roboz and Pitt (1971) made a thorough study of 782 mentally deficient patients living in a residential unit (Kew, Victoria, Australia), 3.6\% were considered to be related to metabolic disorders. After a review of 1,375 institutionalized children, Moser and Wolf (1971) found that metabolic errors and endocrine disorders accounted for $3.1 \%$ of the retarded population. McDonald (1973) surveyed 507 severely retarded children (IQ <50) born in 1958 and living during 1966-1967 in the Province of Quebec. Two percent of these patients were due to metabolic disorders. Hanefeld and Koenig (1974), surveyed 414 retarded children and attributed $4 \%$ of the disorders to metabolic disturbances. Kaveggia et al. (1975) made a serial study of etiological factors in 1,200 severely retarded patients (mean age of 11 years and 2 months) at the Central Wisconsin Colony. Of these, $5.8 \%$ had metabolic diseases (including hypothyroidism), Henderson et al. (1981) carried out biochemical screening for detection of inherited metabolic diseases on urine and blood samples from inmates of the Alexandria Institute for the Mentally Retarded, Cape Town, South Africa. Of the 1,087 patients screened, the overall frequency of metabolic disorders was $0.6 \%$. Rao et al. (1982) conducted biochemical screening of 3,000 mental retardates at the National Institute of Mental Health and Neurosciences in India, 66 cases $(2.2$ $\%$ ) with metabolic defects were detected. In a comprehensive genetic/diagnostic survey of 105 mentally retarded school children aged from 4 to 21 with an IQ of less than 60 , Op't Hof et al. (1985) found that $4.8 \%$ of these children could be at- 
tributed to biochemical disorders. Wuu et al. (1988) screened 4,744 mildly retarded school children in Taiwan, $11(0.23 \%)$ of them were metabolically defective (including congenital hypothyroidism).

In order to explore the possibility of a nation-wide project for chromosomal and biochemical screening of mentally retarded school children in Taiwan, three cities were chosen as our pilot targets. This report describes the screening results for the period from 1988 to 1990.

\section{MATERIALS AND METHODS}

Blood samples. Blood samples from 1,614 mentally retarded school children were collected in Taipei, Taichung and Kaohsiung, three cities located in Northern, Central and Southern Taiwan, respectively. Among these children, 217 were from a School for Mental Retardates in Kaohsiung. Their IQ's were below 50. The remaining 1,397 were students registered in special classes at primary and junior high schools in the three cities and their IQ's ranged from 50 to 75 . A team, including technicians and a pediatrician, was sent to the school each time to collect blood samples and clinical information.

Chromosomal analysis. A volume of $5 \mathrm{ml}$ peripheral blood was collected with a heparinized syringe. The blood samples were sent immediately to a laboratory for culture. The techniques for lymphocyte culture and chromosome preparation were routine and have been reported elsewhere (Wuu et al., 1981). Twenty Gbanded metaphases were analyzed by a Kontron Image Analyzer and two karyotypes were made for each individual. In cases where chromosome abnormalities were encountered, a follow-up study, including genetic counseling, was extended to family members.

Biochemical assays. A smear from each blood sample was collected on filter paper (Toyo Roshi, Tokyo, Japan). After thorough air drying, the filter papers were sent by mail to the screening center at the Clinical Biochemistry Research Laboratory, Department of Medical Research, Veterans General Hospital in Taipei for assay.

Five diseases, namely, phenylketonuria (PKU), homocystinuria, galactosemia, biotinidase deficiency and congenital hypothyroidism (CHT) were selected for screening. The bacterial inhibition assay (Guthrie and Susi, 1963) was applied for phenylketonuria and homocystinuria, the modified Paigen's test for galactosemia (Wuu et al., 1988) and the enzyme immunoassay for thyrotropin for congenital hypothyroidism (Naruse et al., 1982). The details of these screening assays and their confirmatory tests have been reported previously (Wuu et al., 1988). The biotinidase deficiency assay was performed by the colorimetry method (Heard et al., 1984). Dihydropteridine reductase (DHPR) activity in whole blood and dried blood spots were determined according to Arai et al. (1982). 


\section{RESULTS}

\section{Number of blood samples collected}

A total of 1,614 blood samples were collected. Of these, 944 were males and 670 females. It was ubiquitous for all three cities that male patients outnumbered female patients. This is shown in Table 1.

\section{Biochemical findings}

All 1,614 blood samples were subjected to the screening assay for phenylketonuria, homocystinuria, galactosemia, biotinidase deficiency, and congenital hypothyroidism. After confirmatory tests in positive cases, six phenylketonurics and three cases of thyroid dysfunction were found. One of the PKU patients was due to dihydropteridine reductase deficiency, while the other five were classical PKU. The blood DHPR activity of the DHPR deficient PKU case was found to be $<0.06$ $\mathrm{nmol} / \mathrm{min} / \mathrm{mg} \mathrm{Hb}$ (reference range: $2.50-6.93$ ). His urinary biopterin and neopterin contents were determined to be $1.85 \mathrm{mmol} / \mathrm{mol}$ creatinine (ref. range: 0.29 2.61) and $6.73 \mathrm{mmol} / \mathrm{mol}$ creatinine (ref. range: $0.35-2.97$ ), respectively. Among the three thyroid patients, one was congenital hypothyroidjsm and two were trisomic 21 associated with autoimmune thyroiditis. None of the other three diseases was found in this population. The overall incidence for mentally retarded children with PKU and thyroid diseases was $0.56 \%$. According to the range of their IQ, these children can be divided into two groups. The incidence of PKU and thyroid diseases in these two groups is different as shown in Table 2.

\section{Chromosomal findings}

Of the 1,614 blood samples collected, 1,323 were karyotypically analyzed successfully. The indidence of chromosome abnormalities among male and female patients in the three cities is summarized in Table 3.

It is evident that the incidence of chromosome abnormalities in Kaohsiung was higher than that in Taipei and Taichung. This arises from the fact that 217 severe mental retardates (IQ $<50$ ) from Kaohsiung were included, while only mod-

Table 1. The number of blood samples taken from mentally retarded school children in Taipei, Taichung, and Kaohsiung.

\begin{tabular}{lccc}
\hline \multirow{2}{*}{ City } & \multicolumn{3}{c}{ Number of blood samples collected } \\
\cline { 2 - 4 } & Male & Female & Total \\
\hline Taipei & 544 & 327 & 871 \\
Taichung & 182 & 130 & 312 \\
Kaohsiung & 218 & 213 & 431 \\
Total & 944 & 670 & 1,614 \\
\hline
\end{tabular}


Table 2. The relationship between IQ and the incidence of PKU and thyroid diseases (TD).

\begin{tabular}{ccccc}
\hline Group & IQ & $\begin{array}{c}\text { Number of children } \\
\text { screened }\end{array}$ & $\begin{array}{c}\text { Number of } \\
\text { PKU }(\%)\end{array}$ & $\begin{array}{c}\text { Number of } \\
\text { TD }(\%)\end{array}$ \\
\hline 1 & $50-75$ & 1,397 & $4(0.28)$ & $3(0.21)^{\mathrm{a}}$ \\
2 & $<50$ & 217 & $2(0.92)$ & 0 \\
\hline
\end{tabular}

a One was congenital hypothyroidism and two were Down's syndrome associated with autoimmune thyroiditis.

Table 3. The incidence of chromosome abnormalities (CA) in 1,323 mentally retarded school children in Taipei, Taichung, and Kaohsiung.

\begin{tabular}{|c|c|c|c|c|c|c|c|c|c|}
\hline \multirow{3}{*}{ City } & \multicolumn{3}{|c|}{ Male patients screened } & \multicolumn{3}{|c|}{ Female patients screened } & \multicolumn{3}{|c|}{ Total patients screened } \\
\hline & \multirow{2}{*}{ Number } & \multicolumn{2}{|c|}{ with $\mathrm{CA}$} & \multirow{2}{*}{ Number } & \multicolumn{2}{|c|}{ with $\mathrm{CA}$} & \multirow{2}{*}{ Number } & \multicolumn{2}{|c|}{ with $\mathrm{CA}$} \\
\hline & & Number & $\%$ & & Number & $\%$ & & Number & $\%$ \\
\hline Taipei & 383 & 32 & 8.35 & 225 & 20 & 8.89 & 608 & 52 & 8.55 \\
\hline Taichung & 174 & 14 & 8.04 & 129 & 10 & 7.75 & 303 & 24 & 7.92 \\
\hline Kaohsiung & 235 & 27 & 11.49 & 177 & 21 & 11.86 & 412 & 48 & 11.65 \\
\hline Total & 792 & 74 & 9.34 & 531 & 51 & 9.60 & 1,323 & 125 & 9.45 \\
\hline
\end{tabular}

Table 4. Incidence of chromosome abnormalities among two groups of mentally retarded school children based on IQ.

\begin{tabular}{rccc}
\hline \multirow{2}{*}{ IQ } & $\begin{array}{c}\text { Number of patients } \\
\text { screened }\end{array}$ & \multicolumn{2}{c}{ Patients with chromosome abnormalities } \\
\cline { 3 - 4 } & 1,106 & Number & $\%$ \\
\hline $50-75$ & 217 & 87 & 7.87 \\
$<50$ & 38 & 17.51 \\
\hline
\end{tabular}

erately retarded (IQ 50-75) individuals from the other two cities were included. If the incidence is recalculated by IQ grouping, the results are as shown in Table 4. From Table 4, it becomes apparent that the more severe the mental retardation, the higher the incidence of chromosome abnormalities.

Most of the 125 mental retardates with chromosome abnormalities were numerical ones. Sixty-four were trisomy 21. Surprisingly, one girl at age 16 was found to be trisomy 18. Although all the lymphocytes counted had this chromosome number, she might still be a karyotypic mosaic with respect to other tissues. A total of nine abnormal sex chromosome constitutions were found. These include $\mathrm{XXY}, \mathrm{XYY}, \mathrm{XXYY}$, and XXX. Of the 21 translocations, three were Robertsonian Downs involving one 15q21q and two 21q21q, respectively. The prevalence of 
Table 5. Frequencies of different chromosome abnormalities of the 125 mental retardates.

\begin{tabular}{|c|c|}
\hline Type of abnormality & Frequency \\
\hline \multicolumn{2}{|l|}{ Numerical } \\
\hline \multicolumn{2}{|l|}{ Autosome } \\
\hline Trisomy 21 & 64 \\
\hline Trisomy 18 & 1 \\
\hline \multicolumn{2}{|l|}{ Sex chromosome } \\
\hline XYY & 4 \\
\hline $\mathrm{XXY}$ & 3 \\
\hline $\mathrm{XXX}$ & 1 \\
\hline XXYY & 1 \\
\hline \multicolumn{2}{|l|}{ Structural } \\
\hline Deletion & 2 \\
\hline Duplication & 4 \\
\hline Inversion & 15 \\
\hline \multirow[t]{2}{*}{ Translocation } & 21 (including three \\
\hline & Robertsonian Down \\
\hline Others & 9 \\
\hline Total & 125 \\
\hline
\end{tabular}

Down's syndrome in these 1,323 children was approximately $5 \%$. These results are summarized in Table 5.

\section{DISCUSSION}

As we concluded in our previous study, the more severe the degree of mental retardation, the higher the incidence of chromosome abnormalities (Wuu et al., 1984). The present report fully supports this conclusion. In children with IQ's from $50-75,7.87 \%$ had chromosome abnormalities; while in children with IQ of less than $50,17.51 \%$ had chromosome abnormalities. Trisomy 21 was the major category of chromosome abnormalities. Sixty-four were found to have this karyotype among 1,323 (4.83\%) mental retardates.

Although no fragile $X$ analysis was carried out in the present study because of the fact that the Image Analyzer we used was functionally incapable, we did collect blood samples from 131 mentally retarded school children, 111 moderate and 20 severe, in a separate project at a later date for fragile $X$ study. Two fragile $X$ positive cases were observed in the moderate group (unpublished data). Efforts along this line are in progress now.

As for the biochemical screening, one out of the six cases of PKU in the present 
study was caused by tetrabydrobiopterin deficiency, as compared with one out of three in our previous report (Wuu et al., 1988). This is different from the figures reported for Caucasians in which only $1-3 \%$ of the PKU cases are of the tetrahydrobiopterin deficiency type (Dhondt, 1984). Two of the three patients with thyroid dysfunction in the present study had associated trisomy 21 abnormalities. The high association between Down's syndrome and autoimmune thyroid dysfunction has been reported previously (Hsiao et al., 1989).

The main objective of this study was to explore the possibility of a nation-wide screening for chromosomal and biochemical abnormalities among mentally retarded school children. The blood samples were collected locally in Taipei, Taichung, and Kaohsiung. After culturing, staining and slide preparation, the slides were sent by mail from Taipei and Kaohsiung to Taichung for chromosome reading and karyotyping using an Image Analyzer. Only 1,323 of the 1,614 blood samples were karyotyped successfully. A second blood collection was not carried out for most of these failures because of the heavy work load. A pediatrician and one or two technicians from each chromosome laboratory were sent to the school for blood collection. If this screening were extended to cover all the schools islandwide, the present blood collection method would not be practical. While collecting blood on filter paper and sending it by mail to the screening center in Taipei for metabolic screening can be done by school personnel (Wuu et al., 1988), this procedure is not applicable for chromosome screening. Furthermore, chromosome analysis is very tedious and time consuming. We therefore do not suggest that the present screening system be used in a nation-wide chromosome screening of mentally retarded school children in Taiwan.

Acknowledgement This study was supported by a grant from the Department of Health, Executive Yuan, Taiwan.

\section{REFERENCES}

Arai, N., Narisawa, K., Hayakawa, H. and Tada, K. 1982. Hyperphenylalaninemia due to dihydropteridine reductase deficiency: diagnosis by enzyme assays on dried spots. Pediatrics 70: $426-430$.

Cassiman, J.J., Fryns, I.P., de Roover, J. and Berghe, H.V.D. 1975. Sex chromatin and cytogenetic survey of 10,417 adult males and 357 children institutionalized in Belgian institutions for mentally retarded patients. Hum. Genet. 28: 43-48.

Coco, R. and Penchaszadeh, U.B. 1976. Frequency of chromosome aberrations in 131 patients with multiple congenital malformations and mental retardation. J. Pediatr. 89: 325.

Dhondt, J.L. 1984. Tetrahydrobiopterin deficiencies: Preliminary analysis from an international survey. J. Pediatr. 104: 501-508.

Drillien, C.M., Jameson, S. and Wilkinson, E.M. 1966. Studies in mental handicap I. Prevalence and distribution by clinical type and severity of defect. Arch. Dis. Child. $41: 528$.

Guthrie, R. and Susi, A. 1963. A simple phenylalanine method for the detection of phenylketonuria in large population of newborn infants. Pediatrics 32: 338-343.

Hanefeld, F, and Koenig, E. 1974. Ursachen Geistiger Retardierung im Kindesalter (Analyse von 414 faellen). Monatsschr. Kinderheilkd. 122: 679. 
Heard, G.S., McVoy, J.R.S. and Wolf, B. 1984. A screening method for biotinidase deficiency in newborns. Clin. Chem. 30: 125-127.

Henderson, H.E., Goodman, R., Schram, J., Dramond, E. and Daneel, A. 1981. Biochemical screening for inherited metabolic disorders in the mentally retarded. S. Afr. Med.J. 60: 731733.

Hsiao, K.J., Chen, C.H., Liu, T.T., Wu, S.J., Plettner, C. and Clemens, P. 1989. Screening of congenital hypothyroidism, phenylketonuria, galactosemia, homocystinuria, and maple syrup urine disease in moderate to severe mentally retarded Chinese children. J. Formosan Med. Assoc. 88: $18-22$,

Jacobs, P.A., Matsura, J.S., Mayer, M. and Newlands, I.M. 1978. A cytogenetic survey of an institution for the mentally retarded: I. Chromosome abnormalities. Clin. Genet. 13: 37-60.

Kaveggia, E.G., Durkin, M.V., Pendleton, E. and Opitz, J.M. 1975. Diagnostic/genetic studies on 1,224 patients with severe mental retardation. In Proceedings of The Third Congress of The International Association for The Scientific Study of Mental Deficiency, Primrose Daa, ed., Polish Medical Publisher, Warsaw, Vol. 1, pp. 82-93.

Kelly, S. and Swift, H. 1967. Amino acid abnormalities in a mentally retarded population. Am. J. Epidemiol. 85: 250-258.

Moghe, M., Patel, Z.M., Peter, J.J. and Ambani, L.M. 1981. Cytogenetic studies in a selected group of mentally retarded children. Hum. Genet. 58: 184-187.

McDonald, A.D. 1973. Severely retarded children in Quebec: Prevalence, causes and care. Am. J. Ment. Defic. 78: 205-215.

Milunsky, A. 1975. The causes and prevalence of mental retardation. In The Prevantion of Genetic Disease and Mental Retardation, Milunsky, A., ed., W.B. Saunders Co., Philadelphia, pp. $19-50$.

Moser, H.W. and Wolf, P.A. 1971. The nosology of mental retardation: Including the report of a survey of 1,378 mentally retarded individuals at the Walter Fernald State School. Birth Defects (Orig. Art. Ser.) 7: 117-134.

Naruse, H., Irie, M. and Tsuji, A. (eds.) 1982. Neonatal Hypothyroid Screening by Enzyme Immunoassay, Okada Publishing, Tokyo.

Op't Hof, J., Venter, P.A., Du Toit, J.L., Gericke, G.G., Dawson, B., Coetzee, D.J., Mienie, L.J., Marais, C.H. and Reinecke, C.J. 1985. A multidisciplinary diagnostic/genetic study on the 105 patients with mental retardation of the E.S. Le Grange School. J. Ment. Defic. Res. 29: $37-47$.

Rao, S.R., Jayasimha, N. and Subhash, M.N. 1982, Biochemical screening and mental retardation. Indian J. Pediatr. 49: 361-365.

Roboz, P. and Pitt, D. 1971. Studies on 782 cases of mental deficiency. Aust. Pediatr. J. 7: 1219.

Speed, R.M., Johnston, A.W. and Evans, H.J. 1976. Chromosome survey of total population of mentally subnormal in North-East of Scotland. J. Med. Genet. 13: 295-306.

Sutherland, G.R., Murch, A.R., Gardiner, A.J., Carter, R.F. and Wiseman, C. 1976. Cytogenetic survey of a hospital for the mentally retarded. Hum. Genet. 34: 231-245.

Sutherland, G.R. and Wiener, S. 1971. Chromosome studies in a mental deficiency hospital: Total ascertainment. Aust. J. Ment. Res. 1: 246-247.

Wuu, K.D., Hsiao, K.J., Chen, C.H., Hsiao, T.S.H., Chang, C.Y, and Chu, Y.K. 1988. Screening for inherited metabolic diseases and congenital hypothyroidism in 4,744 mentally retarded children in Taiwan. Jpn. J. Human Genet. 33: 33-40.

Wuu, K.D., Lai, H.C., Wuu, S.W. and Hwang, B. 1981. A chromosomal survey of mentally retarded children in Taipei. III. A severely mentally retarded boy with ring chromosome 16. Proc. Nail. Sci, Counc. 5: 243-246.

Wuu, K.D., Wang-Wuu, S. and Liu, I.W. 1984. A cytogenetic survey of mentally retarded children in Taiwan: Final report on the incidence of chromosome abnormalities. Proc. Natl. Sci. Counc. 8: 83-88. 